\title{
Pengembangan Aplikasi Augmented Reality Pengenalan Wisata Kota Manado Berbasis Mobile
}

\author{
Gladly Caren Rorimpandey ${ }^{1}$ \\ Prodi Teknik Informatika FT Universitas Negeri Manado \\ e-mail: gladlycrorimpandey@unima.ac.id \\ Vivi Peggie Rantung ${ }^{2}$ \\ Prodi Teknik Informatika FT Universitas Negeri Manado
}

\begin{abstract}
ABSTRAK
Tujuan penelitian ini adalah untuk mengembangkan suatu aplikasi pengenalan periwiswata Kota Manado dengan menggunakan teknologi augmented reality yang dapat diterapkan atau diakses dengan teknologi mobile (smartphone). Metode Penelitian yang digunakan menggunakan rancangan penelitian MDLC atau Multimedia Development Life Cycle. Rancangan penelitian MDLC ini memiliki 6 tahap yaitu: concept (pengkonsepan), Design (pendesainan), Obtaining Content Material (pengumpulan materi), Assembly (pembuatan), Testing (pengujian), dan Distribution (pendistribusian). Keunggulan pada aplikasi ini yaitu pengenalan pariwisata Kota Manado dapat ditemukan dengan mudah pada smartphone masyarakat dengan fitur dan objek yang didesain menarik dan lebih real dengan menggunakan teknologi Augmented Reality. Selain itu, aplikasi ini juga dapat menuntun masyarakat atau turis Kota Manado untuk menemukan objek Wisata yang dilihat secara augmented reality ke lokasi yang sebenarnya.
\end{abstract}

Kata kunci: Augmented reality, pariwisata, kota manado, MDLC

\section{ABSTRACT}

The aim of this research is to develop an aplication for Manado Tourism using Augmented Reality technology. This aplication can be accessed by smartphone. Research method that is used to achieve the aim is MDLC (Multimedia Development Life Cycle. MDLC) which is designed by 6 steps, they are: Concept,Design, Obtaining Content material, assembly, testing dan Distibution. The advantages of this aplication are the tourism in Manado city can used this application to show the route to reach the destination, design feature and object is more interest and real rather than current media that is used by the government.

Keywords: List up to five keywords here and use comma to separate the keywords

\section{PENDAHULUAN}

Manado saat ini menjadi kota tujuan wisata di Indonesia yang bertumpu pada kekuatan dan keunggulan ekowista. Hal ini didukung juga dengan visi Kota Manado periode kepemimpinan 20162021 didasarkan pada Visi Rencana Pembangunan Jangka Panjang Daerah (RPJPD) Kota Manado tahun 2005-2025 dan gambaran profil dan isu-isu strategis saat ini di Kota Manado, serta memperhitungkan pula kondisi masa datang. Visi RPJPD 2005-2025 yaitu "Manado Pariwisata Dunia", dengan Misi-misinya sebagai berikut:
1. Mewujudkan Pemerintahan Pelayan yang Baik, Bersih serta Demokratis yang Berorientasi Kepariwisataan;

2. Mewujudkan Masyarakat Kota Manado Berdaya Saing yang Mendukung Kepariwisataan;

3. Mewujudkan Lingkungan Asri dan Lestari yang Menopang Kepariwisataan.

Untuk mencapai visi dan misi, maka diperlukan cara promosi ataupun publikasi objek-objek wisata dengan cara memperlihatkan bagian dalam beberapa objek wisata dan kebudayaan agar nampak lebih menarik dengan menggunakan sebuah media. Media yang dimaksud untuk mempermudah 
penyampaian dan selalu harus dikembangkan agar para wisatawan dapat lebih udah mengetahui suatu tempat wisata ataupun objek wisata di Kota Manado. Dengan adanya penambahan teknologi AR yang akan memperkenalkan teknologi tersebut kepada para wisatawan sebagai informasi buat mereka tentang tempat yang akan di kunjungi.

Saat ini, media publikasi yang telah digunakan oleh Dinas Pariwisata Kota Manado adalah periklanan, brosur, dan video. Oleh karena itu, penggunaan teknologi AR merupakan suatu terobosan baru bagi perkembangan media publikasi di Kota Manado. Lebih lanjut, teknologi AR ini akan dapat membantu menarik para wisatawan, oleh karena kemampuan untuk dapat mempresentasikan secara virtual tiga dimensi, real ti me, dan secara interaktif mengenai daerah wisata yang ada di Kota Manado. Dengan adanya penggunaan teknologi AR sebagai salah satu media promosi atau publikasi pada Dinas Pariwisata Kota Manado diharapkan dapat lebih menarik perhatian para wisatawan, baik lokal maupun mancanegara, yang pada akhirnya meningkatkan pendapatan daerah Kota.

\section{METODE}

Penelitian ini didasarkan pada teknologi Augmented Reality yang mengalami perkembangan pesat beberapa tahun terakhir ini. Penelitian yang telah dilakukan adalah sebagai berikut:

1. Pada tahun 2008 ketua peneliti melakukan penelitian mengenai Aplikasi e-Learning Tata Surya berbasis 3D yang dapat dijalankan pada computer atau laptop. Aplikasi tersebut memiliki keunggulan sebagai berikut: objek 3D dapat dikontrol dengan zoom-in, zoomout, dan rotate; memiliki fitur quiz yang dapat mengevaluasi hasil belajar dari siswa yang menggunakan aplikasi tersebut (Rorimpandey G. , 2008).

2. Pada tahun 2008, Institut MinesTelecom melakukan penelitian dengan pembuatan object 3D untuk terrain and cities dengan berbasis animasi frame. Keunggulan pada penelitian ini, selalin objek 3D yang terlihat nyata dengan animasi frame objek 3D dibuat dalam bentuk video bergerak sehingga lebih menarik untuk dipelajari (Preda, 2012).

3. Pada tahun 2015, ketua peneliti bersama dengan Irsan Kapoh membuat penelitian mengenai Augmented Reality for Introduction of Unit System in Personal Computer yang sudah dipaparkan pada Seminar Internasional $1^{\text {st }}$ ICIEVE di Bandung, November 2015 dan telah dipublish dengan indeks Thomson Reuters (Palilingan \& Rorimpandey, 2015).

4. Pada tahun 2016, ketua peneliti bersama dengan Frans Latuny membuat penelitian mengenai Pengembangan Media Pembelajaran Sistem Gerak Manusia berbasis Augmented Reality Mobile. Perbandingan Penelitian yang dilakukan pada tahun 2015 adalah penelitian ini sudah dapat dijalankan pada teknologi mobile dengan sistem operasi Android (Rorimpandey \& Latuny, 2015).

Rancangan penelitian ini mengunakan Multimedia Development Life Cycle (Lhuter, 1994). Metodologi pengembangan ini terdiri dari enam tahap, yaitu concept (pengkonsepan), Design (pendesainan), Obtaining 
Content Material (pengumpulan materi), Assembly (pembuatan), Testing (pengujian), dan Distribution (pendistribusian) seperti pada gambar 1.

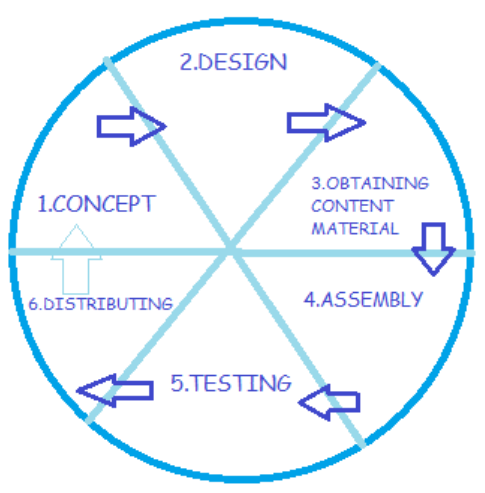

Gambar 1 Multimedia Development Life Cycle (Munir, 2012)

\section{HASIL DAN PEMBAHASAN}

Pada bagian penelitian ini dibahas berdasarkan tahapan metode yang dilakukan, yaitu dimulai dari Pengonsepan sampat Penyaluran (disribusi).

\section{Pengonsepan}

Merancang konsep merupakan tahapan untuk menentukan keseluruhan pesan dan membuat aliran (urutan) pada aplikasi yang dibuat. Untuk itu tim

Tabel 1. Seleksi Media

\begin{tabular}{lll}
\hline \multicolumn{1}{c}{ Media } & Deskripsi \\
\hline Alat Input & $\begin{array}{l}\text { Media yang digunakan untuk } \\
\text { menginput objek AR } \\
\text { objek }\end{array}$ & $\begin{array}{l}\text { Aplikasi ini membutuhkan buku objek untuk } \\
\text { mengeluarkan objek AR baik 3D maupun } \\
\text { Video }\end{array}$ \\
\hline Alat Output & \\
\hline Monitor & $\begin{array}{l}\text { Media yang digunakan untuk } \\
\text { menampilkan interface } \\
\text { aplikasi dan objek Augmented } \\
\text { Reality yang digunakan }\end{array}$ & $\begin{array}{l}\text { Aplikasi menggunakan resolusi layar } \\
\text { tergantung ukuran smartphone }\end{array}$ \\
\hline Speaker & $\begin{array}{l}\text { Media yang digunakan untuk } \\
\text { mendengarkan suara }\end{array}$ & $\begin{array}{l}\text { Aplikasi ini menggunakan suara untuk } \\
\text { menghibur pengguna yang menggunakan } \\
\text { aplikasi ini. }\end{array}$ \\
\hline
\end{tabular}

peneliti merancang konsep dari aplikasi yang akan dikembangkan. Gambar 2 merupakan gambaran konsep pembuatan aplikasi media pembelajaran yang akan dibuat.

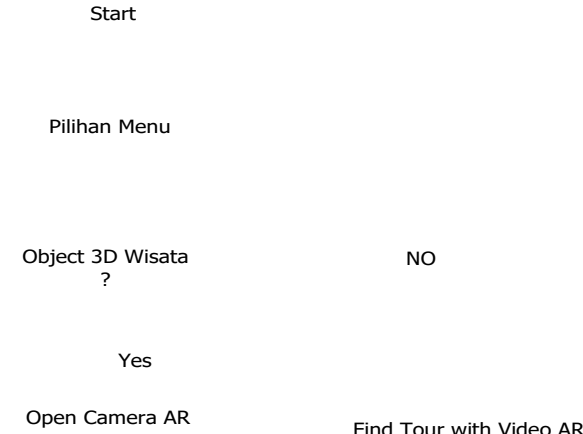

Pilihan Menu

End

Gambar 2 Flowchart Tampilan Aplikasi

Selain itu, pada tahap ini dilakukan identifikasi mengenai media yang akan digunakan guna menunjang pengembangan bahkan implementasi penelitian ini. Tabel 1 menunjukkan hasil seleksi media pada penelitian ini. 


\begin{tabular}{cll}
\hline Media & & Deskripsi \\
\hline Camera & $\begin{array}{l}\text { Media ini menggunakan } \\
\text { camera smartphone }\end{array}$ & $\begin{array}{l}\text { Aplikasi ini menggunakan camera untuk } \\
\text { menampilkan objek AR. }\end{array}$ \\
\hline Aplikasi & & \\
\hline Playstore & $\begin{array}{l}\text { Aplikasi disediakan pada } \\
\text { playstore }\end{array}$ & $\begin{array}{l}\text { Playstore memberi kemudahan bagi } \\
\text { pengguna smartphone untuk dapat } \\
\text { mengunduh sendiri aplikasi yang dibangun. }\end{array}$ \\
\hline $\begin{array}{l}\text { Media } \text { output dan input yang digunakan ini sangat mudah didapatkan, dan biasanya telah } \\
\text { tersedia dalam Smartphone }\end{array}$ & \\
\hline
\end{tabular}

\section{Perencanaan}

Tahap ini meliputi perancangan naskah dan storyboard, merancang interface, pembuatan objek 3 dimensi, pembuatan animasi objek 3 dimensi, dan merancang aplikasi Augmented Reality. Merancang interface meliputi merancang garis, merancang bentuk, merancang warna, merancang kontras nilai, merancang tekstur, dan merancang format. Rancangan untuk menu utama dapat dilihat pada gambar 3 sedangkan rancangan untuk bagian AR dapat dilihat pada gambar 4 .

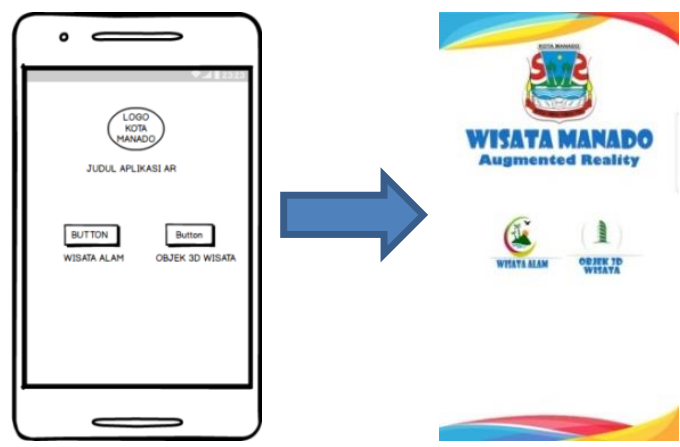

Gambar 3. Menu utama

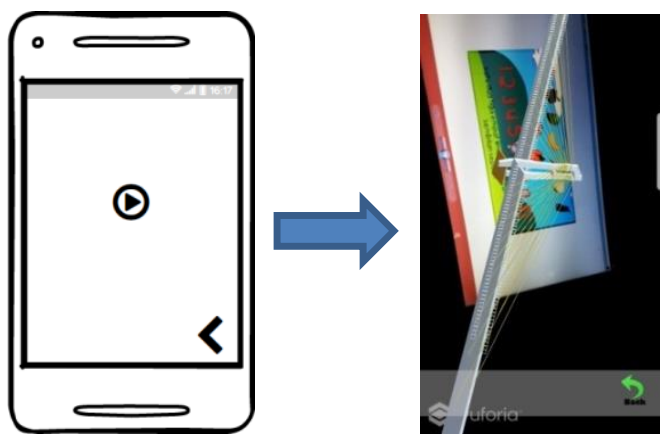

Gambar 4. AR

\section{Pengumpulan Bahan}

Pada tahap ini semua bahan dikumpulkan yang sesuai dengan kebutuhan yang dikerjakan. Bahanbahan tersebut, antara lain gambar clip art, foto atau gambar, animasi, objek 3D, dan lain-lain. Dalam tahap ini peneliti mengambil dari internet bahan-bahan berupa clip art dan foto/gambar baik untuk dijadikan background maupun tombol menu, sedangkan untuk interface aplikasi peneliti menggunakan aplikasi Macromedia Flash dan untuk objek 3D beserta dengan animasinya dibuat sendiri oleh peneliti menggunakan aplikasi Unity. Selain itu, Video dan gambar didapatkan dari berbagai lokasi wisata Kota Manado serta bersumber dari Dinas Pariwisata kota Manado yang diambil saat observasi Penelitian. Berikut rincian bahan dan sumber bahan yang dikumpulkan untuk penelitian ini:

1) Unity game engine $3 \mathrm{D}$ untuk pembuatan aplikasinya

2) Vuforia untuk membuat marker serta database dan license

3) Blender 3D untuk texturing serta modeling karakter yang akan dianimasikan

4) Serta gambar dan Video yang diperlukan untuk pembuatan diambil langsung di tempat wisata ataupun bersumber dari Dinas Pariwisata Kota Manado. 


\section{Assembly}

Pada tahap ini proses pembuatan aplikasi dibuat dengan mengunakan Unity game engine $3 \mathrm{D}$ dengan bahasa pemprograman C\# dan vuforia. Berikut tahapan pembuatan objek 3D untuk jembatan Soekarno yang merupakan objek wisata buatan Kota Manado.

1) Pembuatan Mesh di stage

2) Potong dan buat Mesh menjadi bentuk balok

3) Extrude bagian samping untuk membuat tiang pada sisi kiri dan kanan

4) Extrude lagi dan scale sesuai dengan objek yang akan dibuat

5) Pilih bagian tengah dan extrude untuk membuat jalan

6) Tambahkan Cylinder untuk membuat tali besi. Scale untuk membuat lebih kecil, kemuan scale lagi untuk membuat memanjang

7) Duplicate Cylinder sebanyak yang diinginkan, kemudian ulangi langkah 6).

8) Tahapan terakhir tambahkan texture warna (Perhatikan fitur yang dilingkari garis merah)

\section{Pengujian}

Setelah aplikasi selesai selanjutnya yaitu melakukan pengetesan sistem dan di ujicoba penguna dimana pengujian sistem ini bertujuan untuk mengetahui apakah aplikasi pembelajaran ini sudah sesuai dengan yang direncanakan dan berfungsi secara keseluruhan atau tidak. Maka dari itu peneliti melakukan 3 macam pengujian yaitu pengujian developer, pengujian ahli media, dan pengujian end user test. Minimum Requirement dalam pengujian sistem ini digunakan perangkat Smartphone dengan spesifikasi:
1) Processor $\mathrm{A} 7-30 \mathrm{HC} \quad 4$ core $1.8 \mathrm{GHZ}$

2) Memory RAM 2 GB

3) Sistem Operasi Android Jellybean Ver. 5.0.1

\section{Penyebaran}

Setelah tahap testing selesai, maka dilakukan pendistribution dengan melakukan publish aplikasi dalam bentuk .apk, dan selanjutnya disimpan dalam media penyimpanan. Gambar 5 menunjukan proses render aplikasi ke bentuk .apk.

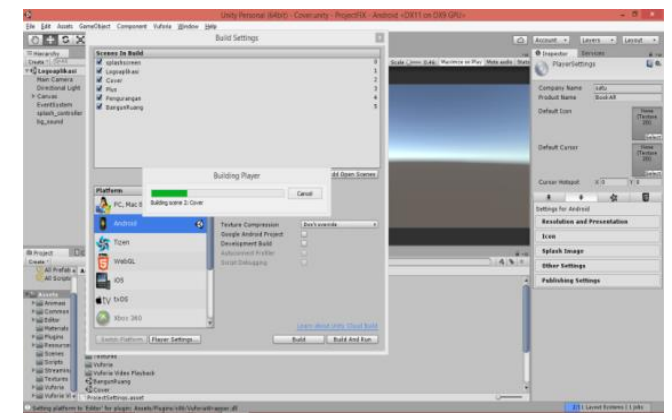

Gambar 5. Proses Render Aplikasi

\section{PENUTUP}

\section{Kesimpulan}

Setelah melakukan penelitian ini maka dapat disimpulkan bahwa:

1. Metode pengembangan sistem MDLC dengan menggunakan 6 tahap: Tahap pengonsepan, tahap perancangan, tahap pengumpulan bahan, tahap pembuatan, tahap pengujian dan tahap penyebaran dapat mengembangkan aplikasi AR pengenalan wisata kota Manado dengan baik dan sesuai kebutuhan wisatawan.

2. Aplikasi AR pengenalan wisata kota Manado dapat menjadi alternative media pengenalan kota Manado yang lebih kreatif dan mudah dijangkau untuk para wisatawan yang sering bepergian 
menggunakan mobile, terlebih mobile dengan OS Android.

\section{Saran}

Setelah melakukan penelitian ini, maka ada beberapa hal yang menjadi kendala dan dapat dilakukan untuk pengembangan aplikasi selanjutnya, yaitu:

1. Waktu dan Dana penelitian yang diberikan masih kurang, sehingga untuk mendapatkan hasil yang lebih baik dapat ditingkatkan untuk penelitian selanjutnya.

2. Objek Wisata dapat ditambahkan sesuai dengan data Dinas Pariwisata Kota Manado untuk penelitian selanjutnya.

\section{DAFTAR PUSTAKA}

Munir, M. (2012). Multimedia Konsep dan Aplikasi dalam Pendidikan. Bandung: Alfa Beta.

Palilingan, V. R., \& Rorimpandey, G. C. (2015). Augmented Reality for Introduction of Unit System in Personal Computer. International Conference on Innovation in Engineering and Vocational Education (ICIEVE 2015) . Bandung: Atlantis Press.

Preda, M. (2012, March 19). MPEG Technologies and roadmap for Augmented Reality. Retrieved July 12, 2017, from SlideShare: https://www.slideshare.net/Marius
Preda/mpeg-technologies-androadmap-for-augmented-reality

Prof. Dr. Munir, M. (2012). Multimedia Konsep dan aplikasi dalam pendidikan. Bandung, Indonesia: Alfa Beta.

Rorimpandey, G. (2008). Aplikasi eLearning Tata Surya berbasis $3 D$. Manado: UNIKA DLSU.

Rorimpandey, G. C., \& Latuny, F. (2015). Pengembangan Media Pembelajaran Sistem Gerak Manusia berbasis Augmented Reality Mobile. Tondano: UNIMA Press.

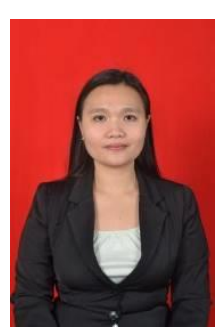

Subari. (2014). Pemanfaatan Teknologi Augmented Reality dalam pembuatan Game. ResearchGate, 34-65.

\section{RIWAYAT HIDUP PENULIS}

Gladly Caren Rorimpandey, ST, MISD Lahir di Manado, 9 Oktober 1986. Dosen prod Teknik Informatika. Studi S1 Bidang Teknik Informatika Universitas Negeri Manado), Manado, lulus tahun (2019); S2 (Information System Development) (HAN University of Applied Sciences,), (Belanda), 2012. 